\title{
Cdk5 Modulates Cocaine Reward, Motivation, and Striatal Neuron Excitability
}

\author{
David R. Benavides, ${ }^{1}$ Jennifer J. Quinn, ${ }^{\star}{ }^{*}$ Ping Zhong, ${ }^{3 \star}$ Ammar H. Hawasli, ${ }^{1}$ Ralph J. DiLeone, ${ }^{1,2}$ Janice W. Kansy, ${ }^{1}$ \\ Peter Olausson, ${ }^{2}$ Zhen Yan, ${ }^{3}$ Jane R. Taylor, ${ }^{2}$ and James A. Bibb ${ }^{1}$ \\ ${ }^{1}$ Department of Psychiatry, The University of Texas Southwestern Medical Center, Dallas, Texas 75390, ${ }^{2}$ Department of Psychiatry, Division of Molecular \\ Psychiatry, Yale University School of Medicine, New Haven, Connecticut 06508, and ${ }^{3}$ Department of Physiology and Biophysics, School of Medicine and \\ Biomedical Sciences, The State University of New York at Buffalo, Buffalo, New York 14214
}

Cyclin-dependent kinase 5 (Cdk5) regulates dopamine neurotransmission and has been suggested to serve as a homeostatic target of chronic psychostimulant exposure. To study the role of Cdk5 in the modulation of the cellular and behavioral effects of psychoactive drugs of abuse, we developed Cre/loxP conditional knock-out systems that allow temporal and spatial control of Cdk 5 expression in the adult brain. Here, we report the generation of $\mathrm{Cdk} 5$ conditional knock-out ( $\mathrm{cKO}$ ) mice using the $\alpha$ CaMKII promoter-driven Cre transgenic line (CaMKII-Cre). In this model system, loss of Cdk 5 in the adult forebrain increased the psychomotor-activating effects of cocaine. Additionally, these CaMKII-Cre Cdk5 cKO mice show enhanced incentive motivation for food as assessed by instrumental responding on a progressive ratio schedule of reinforcement. Behavioral changes were accompanied by increased excitability of medium spiny neurons in the nucleus accumbens (NAc) in Cdk5 cKO mice. To study NAc-specific effects of Cdk5, another model system was used in which recombinant adeno-associated viruses expressing Cre recombinase caused restricted loss of Cdk5 in NAc neurons. Targeted knock-out of $\mathrm{Cdk} 5$ in the NAc facilitated cocaine-induced locomotor sensitization and conditioned place preference for cocaine. These results suggest that $\mathrm{Cdk} 5$ acts as a negative regulator of neuronal excitability in the NAc and that Cdk5 may govern the behavioral effects of cocaine and motivation for reinforcement.

Key words: cocaine; Cdk5; reward; dopamine; nucleus accumbens; excitability

\section{Introduction}

Drugs of abuse induce persistent neuroadaptive alterations in synaptic plasticity within the mesocorticolimbic-striatal circuitry involved in reward-motivated behavior (Hyman and Malenka, 2001; Nestler, 2001; Ungless et al., 2001; Thomas and Malenka, 2003). Chronic cocaine exposure increases the expression of the transcription factor $\Delta \mathrm{FosB}$ in these brain regions (Hope et al., 1994; Chen et al., 1997). An important target of $\Delta$ FosB is the neuronal proline-directed serine/threonine protein kinase cyclin-dependent kinase 5 (Cdk5) (Bibb et al., 2001; Kumar et al., 2005). Cdk5 is activated after association with either of the homologous cofactors p35 (Lew et al., 1994; Tsai et al., 1994) or p39 (Cai et al., 1997). This kinase regulates numerous aspects of neu-

\footnotetext{
Received July 6, 2007; revised 0ct. 4, 2007; accepted 0ct. 5, 2007.

This work was supported by National Institutes of Health Grants to J.A.B. (DA016672), J.R.T. (DA011717), and Z.Y. (MH063128, NS048911). D.R.B. was supported by a predoctoral National Research Service Award from the National Institute on Drug Abuse (DA020199). The floxed Cdk5 mice were a generous gift from P. Greengard (The Rockefeller University, New York, NY). We thank C. Steffen and J. Pick for assistance with animal husbandry, T. Sasaki and D. Theobald for technical assistance with behavioral assays, D. C. Lagace for help with immunohistochemistry, and P. Greengard for DARPP-32 antibodies. We are also grateful to the Medical Scientist Training Program at The University of Texas Southwestern Medical Center.

*J.J.Q. and P.Z. contributed equally to this work.

Correspondence should be addressed to Dr. James A. Bibb, Department of Psychiatry, The University of Texas Southwestern Medical Center, 5323 Harry Hines Boulevard, NC5.410, Dallas, TX 75390-9070. E-mail: james.bibb@utsouthwestern.edu.

DOI:10.1523/JNEUROSCI.4061-07.2007

Copyright $\odot 2007$ Society for Neuroscience 0270-6474/07/2712967-10\$15.00/0
}

ronal function, including cAMP and $\mathrm{Ca}^{2+}$ signal transduction cascades (for review, see Bibb, 2003), presynaptic machinery (Tan et al., 2003; Tomizawa et al., 2003; Evans and Cousin, 2007), and synaptic plasticity (Fischer et al., 2005; Centonze et al., 2006; Hawasli et al., 2007). In the striatum, Cdk5 controls dopamine neurotransmission through the regulation of the protein phosphatase- 1 inhibitor, DARPP-32 (Bibb et al., 1999), as well as presynaptic components of dopamine synthesis and release (Chergui et al., 2004; Kansy et al., 2004; Moy and Tsai, 2004). Thus, Cdk5 may regulate reward-related behaviors through numerous neurobiochemical pathways in the reward circuitry.

The perinatal lethality and congenital defects associated with Cdk5 or Cdk5-cofactor knock-out mice (Nikolic et al., 1996; Ohshima et al., 1996; Kwon and Tsai, 1998; Ko et al., 2001) have hampered the use of behavioral paradigms to study Cdk5 function. To circumvent this issue, we generated conditional knockout (cKO) systems that allow deletion of Cdk5 from specific brain regions in the adult animal, after normal CNS development. These models were specifically designed to avoid congenital issues of Cdk 5 loss and allow the investigation of the effect of Cdk5 deletion from the mature brain on reward-related behavioral paradigms. Here, we report that CaMKII-Cre Cdk5 cKO mice showed enhanced locomotor responses to cocaine and intensified motivation for food reinforcement. Furthermore, nucleus accumbens (NAc) medium spiny neurons from Cdk5 cKO mice exhibited increased intrinsic excitability. These data suggest that 
Cdk5 activity within NAc neurons may be important in the modulation of reward-related behaviors.

Studies that have used pharmacological inhibitors of Cdk5 have suggested that inhibition of this kinase in the NAc enhances several behavioral responses to cocaine (Bibb et al., 2001; Taylor et al., 2007). However, such pharmacological approaches were unable to distinguish the effects of Cdk5 inhibition in presynaptic versus postsynaptic compartments. To investigate the role of Cdk5 specifically in NAc neurons in cocaine-related behaviors, we used targeted delivery of recombinant adeno-associated virus (rAAV) expressing Cre recombinase to the NAc of conditional Cdk5 mice. This approach allowed temporally controlled and spatially restricted loss of Cdk5 in the postsynaptic compartment of NAc neurons. This manipulation produced an enhancement in the locomotor-activating effects of repeated cocaine exposure and facilitated cocaine-induced conditioned place preference. Together, these findings suggest that Cdk5-dependent modulation of neuronal excitability in the NAc is involved in the behavioral responses to cocaine, cocaine-associated stimuli, and motivation for food reinforcement.

\section{Materials and Methods \\ Animals and animal care}

The conditional Cdk5 allele was generated using a Cre/loxP gene targeting strategy as described previously (Wattler et al., 1999). This floxed Cdk5 allele (fCdk5) is efficiently excised by Cre recombinase in vivo (Hawasli et al., 2007). Cdk5 alleles were identified by a PCR-based genotyping strategy as described previously (Hawasli et al., 2007) (see supplemental methods, available at www.jneurosci.org as supplemental material). fCdk5 mice were generated in 129/Sv and C57BL/6J hybrid mice and backcrossed several generations to C57BL/6J. Mice were maintained on a mixed background of C57BL/6J and 129/Sv and were group housed on a $12 \mathrm{~h}$ light/dark cycle with access to food and water ad libitum. All procedures were performed during the light cycle. Behavioral manipulations were approved by University of Texas Southwestern and Yale University Institutional Animal Care and Use Committees and conducted in accordance with the applicable portions of the National Institutes of Health Guide for the Care and Use of Laboratory Animals. All drugs and chemicals were obtained from Sigma-Aldrich (St. Louis, MO) unless otherwise noted.

\section{Generation of conditional Cdk5 knock-out mice}

Homozygous fCdk5 mice were bred with mice expressing Cre recombinase under the control of the $\alpha$ CaMKII promoter (Tsien et al., 1996) to generate Cdk5 cKO mice. The CaMKII-Cre T50 line (provided by L. F. Parada, University of Texas Southwestern) was chosen to mediate recombination of Cdk5 in the postnatal forebrain. This line has been shown to exhibit Cre activity beginning postnatal day 18 (P18) and proceeding through P60 (Luikart et al., 2005), thus circumventing developmental issues regarding loss of Cdk5. Littermate, homozygous fCdk5 mice lacking the CaMKII-Cre transgene served as controls. Adult (10-12 weeks old) male mice were used for all experiments. The transgenic CaMKII-Cre and R26R-EYFP mice (provided by A. J. Eisch, University of Texas Southwestern) were genotyped using PCR-based strategies (see supplemental methods, available at www.jneurosci.org as supplemental material).

\section{Generation of NAc-specific Cdk5 knock-out mice using rAAV}

Adeno-associated viral vectors were infused into the brain via stereotaxic surgical procedures as described previously (Hommel et al., 2003; Berton et al., 2006). Recombinant vectors encoding enhanced green fluorescent protein (EGFP), a Cre recombinase/EGFP chimeric protein (EGFPCre), or Cre were derived by cloning cDNAs into the pAAV-lacZ amplicon (Stratagene, La Jolla, CA). Serotype 2 rAAVs were generated using a modified triple transfection method in HEK293 cells, as described previously (Zolotukhin et al., 1999). After transfection, HEK293 cells were lysed, and rAAV was purified via iodixanol density gradient to produce viral titers of $10^{11}$ to $10^{12} \mathrm{pfu} / \mathrm{ml}$.
These rAAV particles transduce neurons with high efficiency in vivo (Burger et al., 2004) and maintain detectable levels of expression in the brain for up to 12 months after infection (R. J. DiLeone, unpublished observations). NAc-specific Cdk5 knock-out (NAc-KO) was achieved in adult (6-8 weeks old), male homozygous fCdk 5 mice via bilateral stereotaxic delivery of rAAV $\left(\sim 4 \times 10^{8}\right.$ particles, $0.4 \mu \mathrm{l} /$ hemisphere $)$ to the NAc core (coordinates from bregma at skull surface: +1.6 to $+1.9 \mathrm{~mm}$ anteroposterior, $+1.5 \mathrm{~mm}$ lateral, $-4.5 \mathrm{~mm}$ dorsoventral; $10^{\circ}$ angle of entry). Surgical procedures were performed under aseptic conditions after anesthesia with Avertin $(240 \mathrm{mg} / \mathrm{kg})$. Delivery of rAAV expressing Cre produced focal, conditional knock-out of Cdk5 in the NAc, and littermate fCdk5 mice transduced with rAAV-EGFP served as controls.

\section{Histological procedures and immunoblotting}

In situ hybridizations for Cdk5 and Cre were conducted as described previously (Gold et al., 1997; Hawasli et al., 2007). Briefly, ${ }^{35}$ S-UTPlabeled riboprobes were hybridized with fresh cryosections for $16-18 \mathrm{~h}$ at $60^{\circ} \mathrm{C}$. After hybridization, slides were washed in sodium chloride/sodium citrate buffer, dried, and exposed to film. Autoradiograms were scanned and semiquantitative analysis was conducted using Image J software (NIH). Immunohistochemistry was performed essentially as described previously (Kansy et al., 2006). Primary antibody incubations were conducted overnight at $4^{\circ} \mathrm{C}$ using antibodies to GFP (1:1000; AbCam, Cambridge, UK) and NeuN (1:100; AbCam). Slides were washed in PBS and incubated with Cy5- or Cy2-conjugated secondary antibody (1:200; Jackson ImmunoResearch, West Grove, PA) before dehydration and coverslipping in DPX. Images were captured and analyzed using a scanning laser confocal microscope. Immunoblotting was performed as described previously (Sahin et al., 2004). Tissue homogenates were prepared from control and Cdk5 $\mathrm{cKO}$ mice, and equal amounts of total protein were resolved by SDS-PAGE and transferred to nitrocellulose membranes. Membranes were probed with antibodies to Cdk5 (1:500; Santa Cruz, Santa Cruz, CA), $\beta$-actin (1:500,000; Abcam), phosphoThr75 and total DARPP-32 (1:5000, provided by P. Greengard, Rockefeller University, New York, NY) washed, and incubated with HRPconjugated secondary antibodies and detected using ECL chemiluminescence (GE Healthcare, Piscataway, NJ). Membranes were exposed to autoradiographic film and resulting autoradiograms were scanned and analyzed using Image (NIH). Cdk5 protein levels are represented as values normalized to $\beta$-actin, whereas phospho-Thr75 is normalized to total DARRP-32.

\section{Behavioral procedures}

Cocaine-induced locomotor activity assay. Horizontal locomotor activity was monitored in standard polypropylene cages $(15 \times 25 \mathrm{~cm})$ in chambers equipped with infrared photobeams to monitor activity using a computer (Photobeam Analysis Software, San Diego Instruments, San Diego, CA). Locomotor activity was measured as sequential adjacent beam breaks and reported as locomotor counts. There were no differences between control and Cdk5 knock-out mice in the time spent executing repetitive, fine movements (stereotypy) in any of the experiments conducted. In one experiment, a Latin-square cross-over design was used to evaluate CaMKII-Cre Cdk $5 \mathrm{cKO}$ mice, with one testing session per day for $8 \mathrm{~d}$ ( $n=10$ per group). For each experimental day, animals were placed in the chamber and motor activity was recorded for $1 \mathrm{~h}$, at which point a single intraperitoneal $(5 \mathrm{ml} / \mathrm{kg})$ injection was delivered, and the animal was returned to the chamber for $1 \mathrm{~h}$. During the first $3 \mathrm{~d}$, mice were habituated to saline injections, and the next $5 \mathrm{~d}$, they were given injections of cocaine $(0,2.5,5,10,20 \mathrm{mg} / \mathrm{kg})$. Drug doses were randomized among the groups to prevent order or carryover effects on locomotor responses.

Instrumental responding and progressive ratio testing. Instrumental responding experiments for food-reinforced reward in CaMKII-Cre Cdk5 cKO mice were performed using operant chambers for mice $(16 \times 14 \times$ $14.5 \mathrm{~cm}$ ) equipped with a food pellet dispenser and three nose-poke apertures. Throughout the experiment, only the left or right positions were reinforced, and the position of the active nose poke was counterbalanced for all groups to prevent positional bias. Nose pokes were detected by photobeams within the receptacle linked to computer software 
(Med Associates, St. Albans, VT). During the $5 \mathrm{~d}$ before the start of the experiment, all animals underwent food restriction to $85-90 \%$ of baseline weight ( $n=16-20$ per group). The animals were habituated to testing chambers and pellet magazine before training. Animals were trained over fixed and random interval reinforcement schedules consisting of $5 \mathrm{~d}$ of each of the following: fixed-interval $20 \mathrm{~s}$ (FI20), randominterval $40 \mathrm{~s}$ (RI40), random-interval $60 \mathrm{~s}$ (RI60), and reversal training, during which the active and inactive responses were switched and an RI60 schedule was used. After training, the animals were tested for progressive ratio $(\mathrm{PR})$ responding across $3 \mathrm{~d}$. The $\mathrm{PR}$ sessions began with a fixed ratio (FR) 1 schedule for the first reinforcer and increased by 4 to obtain each subsequent reinforcer (i.e., $1,5,9, \ldots, x+4$ responses). The $\mathrm{PR}$ responding test was conducted as an open session, such that the experiment was terminated when each animal reached its final breakpoint ratio. The breakpoint ratio was achieved when the animal discontinued responding in the active nose poke for a continuous $5 \mathrm{~min}$ period. Weeks after the PR responding test, the same animals were used for the reinforcer devaluation experiment. In this experiment, animals were fed before PR responding for food-reinforced instrumental responding. The prefeeding reinforcer devaluation experiment was performed by allowing animals to eat unlimited food pellets in a novel context for $1 \mathrm{~h}$ (with water available) before PR testing.

Cocaine-induced locomotor sensitization assay. Locomotor sensitization to cocaine ( 10 or $15 \mathrm{mg} / \mathrm{kg}$ ) was examined in NAc-KO mice using an experimental design similar to that described above (see Cocaineinduced locomotor activity). In these experiments, subjects were habituated to saline for $4 \mathrm{~d}$, followed by injection of cocaine over the following $5 \mathrm{~d}$ ( $n=16-19$ per group). For each experimental day, animals were placed in the chamber and motor activity was recorded for $30 \mathrm{~min}$, at which point a single intraperitoneal $(5 \mathrm{ml} / \mathrm{kg})$ injection was delivered and the animal was returned to the chamber for $1 \mathrm{~h}$.

Cocaine-conditioned place preference assay. The conditioned place preference assay was used to study NAc-KO responses to reward-associated stimuli. The place preference chamber contained two large compartments with distinct visual and tactile cues, separated by a smaller, center compartment. Before drug conditioning, animals were placed in the center area to record exploration of all compartments for 20 min using computer software (Med Associates). An unbiased, counterbalanced protocol was used to ensure that no preference for any compartment was observed in any group during the pretraining trial. For drug-context training sessions, partitions were put in place to confine subjects in a specific compartment of the apparatus. Alternating for $4 \mathrm{~d}$, mice were conditioned to one compartment with saline or to the other compartment with cocaine $(0,2.5,5,20 \mathrm{mg} / \mathrm{kg}$, i.p.) for $25 \mathrm{~min}(n=9-19$ per group). Mice were placed into the center area $24 \mathrm{~h}$ after the last conditioning session, and the time spent in each compartment was recorded for $20 \mathrm{~min}$. A conditioning score was calculated for each animal by subtracting the time spent in the drug-paired compartment before training from the time spent after training. Additional behavioral procedural methods are provided in supplemental methods (available at www.jneurosci.org as supplemental material).

\section{Preparation of acute striatal slices and electrophysiology}

Acute slices and whole-cell patch-clamp recordings were performed in CaMKII-Cre Cdk5 cKO mice, according to methods described previously (Zhong et al., 2003). Briefly, mice were anesthetized by inhaling 2-bromo-2-chloro-1,1,1-trifluoroethane (1 ml/100 g) and decapitated. Brains were then quickly removed, iced, and sliced with a VP1000S Vibratome (Leica; Nussloch, Germany). Slices $(400 \mu \mathrm{m})$ were incubated for $1-5 \mathrm{~h}$ at room temperature $\left(20-22^{\circ} \mathrm{C}\right)$ in a $\mathrm{NaHCO}_{3}$-buffered saline bubbled with $95 \% \mathrm{O}_{2}, 5 \% \mathrm{CO}_{2}$. To measure intrinsic excitability, current-clamp recordings were conducted using patch electrodes filled with an internal solution containing the following (in mM): $60 \mathrm{~K}_{2} \mathrm{SO}_{4}, 60$ $\mathrm{N}$-methyl-D-glucamine, $40 \mathrm{HEPES}, 4 \mathrm{MgCl}_{2}, 0.5$ BAPTA, 12 phosphocreatine, $2 \mathrm{Na}_{2} \mathrm{ATP}, 0.2 \mathrm{Na}_{3} \mathrm{GTP}$, and 0.1 leupeptin, $\mathrm{pH}$ 7.2-7.3, 265-270 $\mathrm{mOsm} / \mathrm{L}$. Slices were positioned in a heated $\left(30^{\circ} \mathrm{C}\right)$ perfusion chamber attached to the fixed-stage of an upright microscope (Olympus; Center Valley, PA) and submerged in continuously flowing oxygenated artificial CSF. Cells were visualized with a $40 \times$ water-immersion lens and illumi- nated with near-infrared (IR) light, and the image was detected with an IR-sensitive CCD camera. Recordings were made with Multiclamp 700A amplifier (Axon Instruments, Sunnyvale, CA) that was controlled and monitored with a computer running pClamp (v. 8) with a DigiData 1322A interface (Axon Instruments). Tight seals (2-5 G $\Omega$ ) from visualized neurons were obtained by inducing negative pressure. The membrane was disrupted with additional suction, and the wholecell configuration was obtained. The access resistances ranged from 10 to $15 \mathrm{M} \Omega$.

\section{Statistical analysis}

Experimental data were analyzed using two-way ANOVA followed by Bonferroni test, ANOVA followed by Tukey or Newman-Keuls test, or Student's $t$ test using GraphPad Prism 4.0 and SPSS 12.0 for Windows software. Two-way ANOVA for repeated measures (RM) was used where appropriate (i.e., response to repeated injections, performance on consecutive days, etc.). Data are reported as mean \pm SEM for each measure. Each sample size is indicated. A value of $p \leq 0.05$ was considered statistically significant.

\section{Results}

\section{Generation of a conditional Cdk5 knock-out mouse model}

To achieve conditional loss of Cdk5, the endogenous gene encoding the protein kinase was first replaced with a targeted allele in which loxP sites flank exons $2-5$ (Fig. $1 A$ ). This fCdk5 allele is subject to excision by Cre recombinase, resulting in knock-out of Cdk5. The transgenic line expressing Cre under the control of the $\alpha$ CaMKII promoter (CaMKII-Cre) was used to mediate excision of Cdk5 in the adult brain. Using this transgenic strategy, recombination of the fCdk5 allele was achieved throughout the forebrain of adult CaMKII-Cre/fCdk5 transgenic mice (Fig. $1 B$ ). Cdk 5 cKO mice showed significant reduction in Cdk 5 mRNA in striatum $(32.4 \pm 4.8 \%)$, cortex $(39.5 \pm 5.3 \%)$, and hippocampus $(26.1 \pm 4.7 \%)$ compared with littermates lacking the CaMKIICre transgene (Fig. $1 B$ ). No alteration was observed in the level of Cdk5 mRNA in the cerebellum of cKO mice $(101 \pm 4.9 \%$ of littermate control). These data indicate that $\mathrm{Cdk} 5$ was selectively decreased throughout structures of the adult forebrain in Cdk5 cKO mice. The decrease in striatal Cdk5 mRNA corresponded to a similar decrease in protein level in striatal tissue lysates (50.7 \pm $17.0 \%$ compared with littermate control) (Fig. 1C). Decreases in $\mathrm{Cdk} 5$ protein also correlated well with reduced Cdk 5 activity in tissue homogenates from inducible Cdk5 conditional knock-out mice (Hawasli et al., 2007). Furthermore, Cdk5 cKO mice showed a decrease in Cdk5-dependent phosphorylation of Thr75 DARPP-32 in striatal tissue lysates $(62.9 \pm 0.05 \%$ of littermate control) (Fig. 1C). Consequently, transgenic CaMKII-Cre Cdk5 cKO mice showed reduction in Cdk5 mRNA, protein, and kinase activity in forebrain structures.

To further define the activity of the CaMKII-Cre, this Cre line was crossed to a transgenic reporter line that expresses enhanced yellow fluorescence protein (EYFP) after Cre-mediated recombination (R26R-EYFP) (Srinivas et al., 2001). The R26R-EYFP mouse harbors a loxP flanked stop-EYFP cassette at the R26R locus. Cre-mediated excision of this stop signal results in fluorescence attributable to EYFP expression. Cre activity was visualized in $\sim 60 \%$ of the cells of the dorsal striatum and NAc of CaMKIICre/R26R-EYFP mice at 10-12 weeks of age (Fig. 1D), consistent with previous observations for this transgenic line (Monteggia et al., 2007). These data suggest that the CaMKII-Cre transgene mediates Cdk5 knock-out in a mosaic population of neurons within the striatum. 
Effect of conditional Cdk5 knock-out in adult forebrain on psychomotor stimulant effects of cocaine

To assess the effect of loss of Cdk5 on the locomotor-activating effects of cocaine, a randomized Latin-square dose-response experiment was conducted using transgenic Cdk5 cKO mice. Mice were habituated to locomotor activity chambers and received intraperitoneal injections of saline for $3 \mathrm{~d}$. On each of the subsequent $5 \mathrm{~d}$, mice were given a single injection of cocaine $(2.5,5,10$, or $20 \mathrm{mg} / \mathrm{kg})$ or saline, and locomotor responses were recorded for $60 \mathrm{~min}$. Statistical analyses revealed a significant effect of treatment in both control and Cdk5 $\mathrm{cKO}$ mice $\left(F_{(4,76)}=3.62\right.$; $p<0.0001$, two-way RM ANOVA). Animals displayed elevated responses to escalating doses of cocaine administration (Fig. 2A). There was no significant effect of genotype $\left(F_{(1,76)}=2.81 ; p=0.10\right)$ and no interaction between genotype and treatment day $\left(F_{(4,76)}=2.07 ; p=0.09\right)$. However, conditional loss of Cdk5 produced a dramatic elevation in response to $20 \mathrm{mg} / \mathrm{kg}$ cocaine compared with control mice (330 \pm 80.3 for control vs $739.7 \pm 207.2$ for cKO) (Fig. $2 B$ ). No difference was detected in response to saline injection $(94.1 \pm 14.0$ for control vs $153.8 \pm 37.0$ for $\mathrm{cKO}$ ) (Fig. 2C), indicating that the increased locomotion in $\mathrm{Cdk} 5 \mathrm{cKO}$ mice is not caused by nonspecific hyperactivity resulting from handling or injection. These data indicate that Cdk5 loss in the forebrain produced an enhancement in locomotor responsiveness to acute exposure to a high dose of cocaine. These findings provide direct evidence for the involvement of Cdk5 in the regulation of behavioral responses to cocaine.

Effect of Cdk5 loss in adult forebrain on motivation for food-reinforced progressive ratio responding Drugs of abuse activate the neural circuitry involved in normal incentive motivation for reinforcers such as food (Kelley and Berridge, 2002). Instrumental responding on progressive ratio schedules has been widely used to study motivation. To evaluate the involvement of Cdk5 in motivation, CaMKII-Cre Cdk5 cKO mice and littermate controls were trained to nose poke for food reinforcement and tested for 3 consecutive days under a progressive ratio schedule of reinforcement which provides a measure of how hard an animal is willing to work for the reward. Cdk5 cKO mice did not differ from controls in their acquisition of instrumental responding (supplemental Fig. $1 \mathrm{~A}$, available at www.jneurosci.org as supplemental material). In contrast, loss of Cdk5 produced dramatically elevated active responses compared with controls on all days tested on progressive ratio responding (3209.1 $\pm 662.6,1886.2 \pm 533.9$, and $1901.7 \pm$ 546.0 for cKO vs $1057.1 \pm 214.0,375.3 \pm 80.7$, and $432.6 \pm$

A
Control
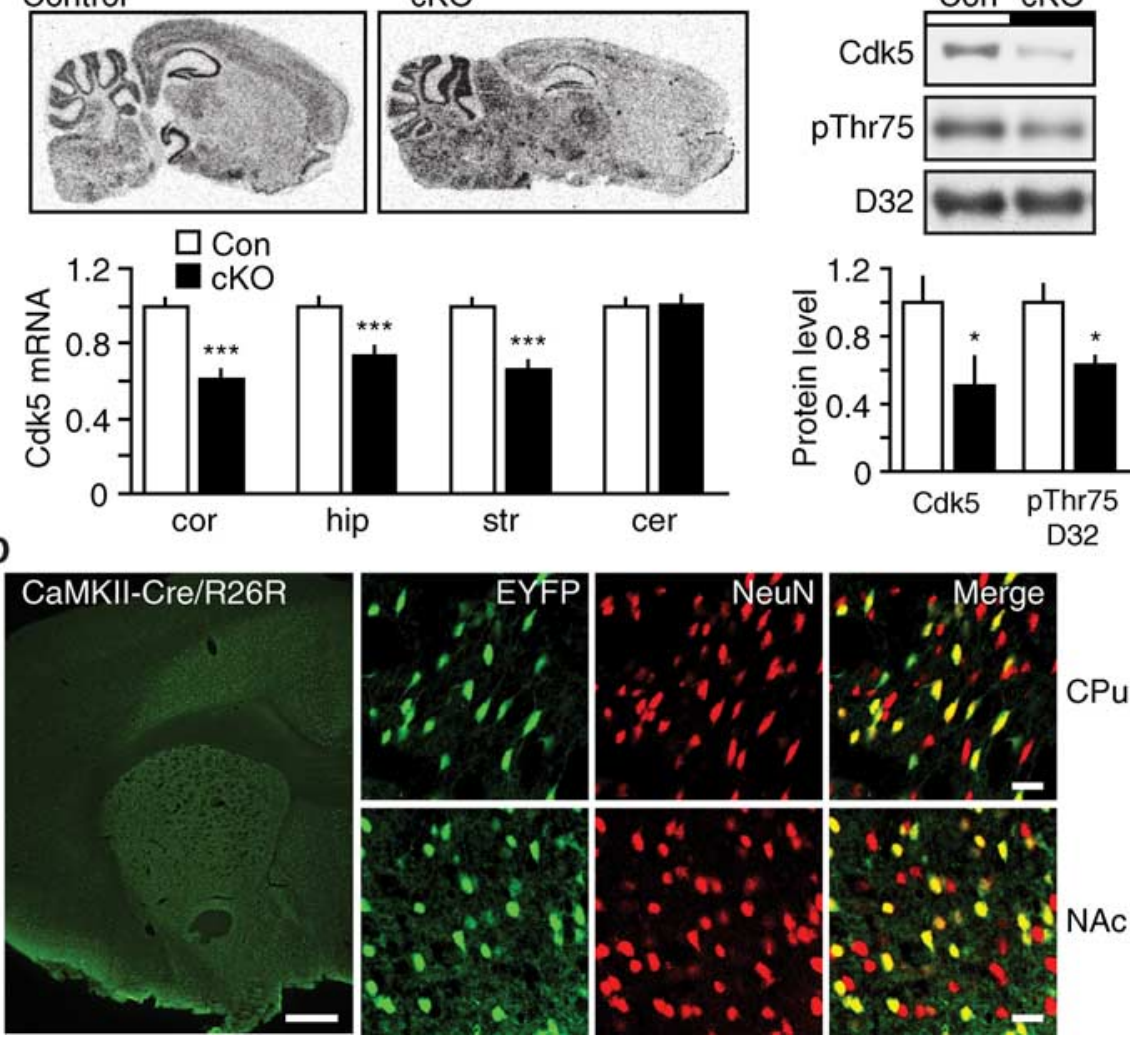

Figure 1. Generation of conditional C $\mathrm{dk} 5$ knock-out mouse model. $\boldsymbol{A}$, Diagram depicting targeting strategy for generation of conditional C $\mathrm{dk} 5$ allele. The targeted fCdk5 allele contains loxP sites (arrowheads) flanking exons 2-5. B, Utilization of transgenic CaMKII-Cre to mediate excision of Cdk5 in adult brain. Representative in situ hybridization of sagittal brain sections from control and Cdk5 cKO mice using (dk5 riboprobe. The graph depicts normalized Cdk5 mRNA levels \pm SEM in cortex (cor), hippocampus Student's $t$ test, $n=5-7$ per group). C, Quantitative immunoblots of (dk5 and phospho-Thr75 DARPP-32 (pThr75 D32) in striata mogenates from control and cKO mice. Representative immunoblots (top) and quantitation (bottom) are shown for each ( ${ }^{*} p<$ with control, Student's $t$ test, $n=5-8$ per group). $D$, Immunostaining for EYFP (green) and the neuronal marker, NeuN (red), in CaMKII-Cre/R26R-EYFP reporter mice. Cre activity is shown in EYFP-positive cells (green) in the caudoputamen (CPu), NAc, and cortex at low magnification (left). EYFP/NeuN double-positive cells (yellow) are shown throughout the CPU and NAc at high resolution (right). Scale bars: $500 \mu \mathrm{m}$ (left, low magnification), $20 \mu \mathrm{m}$ (right, high magnification).

133.1 for control on day 1, 2, and 3, respectively) (Fig. 3A) Cdk5 cKO mice also showed significantly elevated inactive responses on day $1(471.1 \pm 117.5$ for cKO vs $194.7 \pm 43.3$ for control) (Fig. 3A), although this effect did not persist over the second and third day of testing. Most striking was that Cdk5 cKO mice achieved significantly higher breakpoints compared with controls over all $3 \mathrm{~d}$ of testing $(142.0 \pm 17.5,92.3 \pm 14.9$, and $101.3 \pm 16.2$ for $\mathrm{cKO}$ vs $79.2 \pm 9.3,46.2 \pm 6.1$, and $47.0 \pm$ 7.5 for control on days 1, 2, and 3, respectively) (Fig. 3B). No differences in weight were observed between groups (supplemental Fig. $1 B$, available at www.jneurosci.org as supplemental material), suggesting that the enhanced performance in Cdk5 cKO mice was not likely attributable to alterations in appetite or hunger. These data indicate that loss of Cdk5 in the 
A

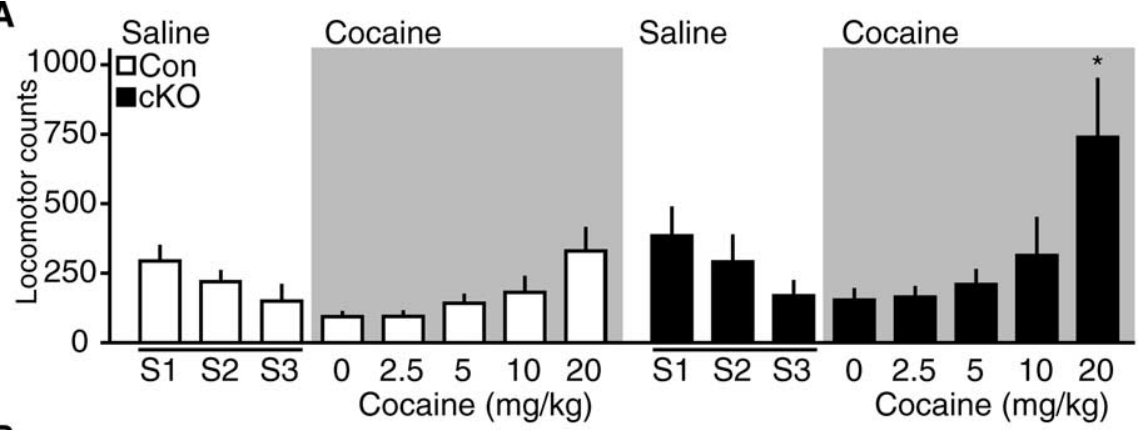

B$$
\text { B }
$$
Before Cocaine $(\mathrm{mg} / \mathrm{kg})$
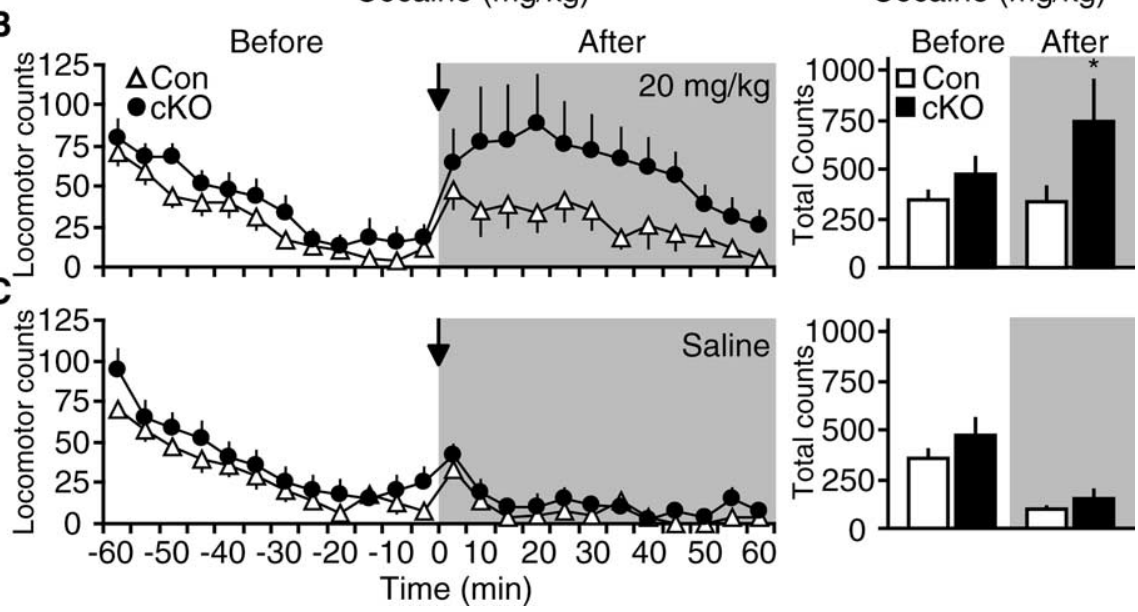

Figure 2. Effect of transgenic Cdk5 cKO on cocaine-induced locomotor activity. $\boldsymbol{A}$, Locomotor responses of control (Con) and CaMKII-Cre Cdk5 cKO mice to saline and cocaine injections in Latin-square dose-response experiment. Mice were habituated to saline injections for 3 consecutive days (S1-S3), followed by cocaine injections in the Latin-square doseresponse (gray background). The graph depicts mean locomotor counts \pm SEM for 60 min after injection with saline or the drug dose indicated $\left({ }^{*} p<0.05\right.$ compared with control, post hoc Bonferroni, $n=10$ per group). $\boldsymbol{B}$, Time course of locomotor activity in response to administration of $20 \mathrm{mg} / \mathrm{kg}$ cocaine. The graph on the left depicts mean locomotor counts \pm SEM over 60 min before (white background) and after (gray background) injection of control or cK0 groups. Arrow denotes time of injection in each graph. Cumulative locomotor counts \pm SEM over 60 min are displayed in histograms at right ( ${ }^{*} p<0.05$, Student's $t$ test, $n=10$ per group). $C$, Locomotor activity response to saline injection over the same time course as $\boldsymbol{B}$ with data summarized in histograms (right).
Neurons in the NAc from Cdk5 cKO mice exhibit increased excitability

To understand possible mechanisms involved in these behavioral effects, we examined the effect of Cdk5 loss on the physiological state of NAc neurons. For this analysis, patch-clamp recordings were performed in NAc medium spiny neurons from CaMKII-Cre Cdk 5 cKOs to examine the potential changes in their intrinsic excitability. When compared with cells recorded from control mice, loss of Cdk5 did not alter the current-voltage relationship (Fig. 4A), resting membrane potential, or action potential waveform properties (Table 1) in NAc medium spiny neurons. However, there was a dramatic increase in the intrinsic excitability of NAc neurons as measured by the number of spikes evoked by injection of depolarizing current steps (Fig. 4B). Loss of Cdk5 increased the firing rate of NAc neurons by $135-210 \%$ in response to $180-220$ pA current injections, compared with NAc neurons from control mice (Fig. 4C). In addition, cells from $\mathrm{Cdk} 5 \mathrm{cKO}$ slices displayed a reduced threshold to elicit a spike compared with controls $(137.6 \pm 5.3 \mathrm{pA}$ in cKO vs $158.3 \pm 4.2 \mathrm{pA}$ in control), as well as a decreased latency to fire in response to $180 \mathrm{pA}$ current injection (Table 1). Thus, NAc neurons from Cdk5 cKO mice show increases in neuronal excitability. These data suggest that $\mathrm{Cdk} 5$ exerts an inhibitory effect on the basal intrinsic excitability of NAc neurons that may be related to behavioral responses to rewarding stimuli, including cocaine and natural reinforcers like food. adult forebrain increases the motivation for goal-directed instrumental responding for appetitive reinforcement.

We also sought to specifically explore motivational influences on goal-directed responding in Cdk $5 \mathrm{cKO}$ mice by assessing the ability of posttraining reinforcer devaluation to alter progressive ratio responding. This satiety-induced reinforcer devaluation experiment was conducted by switching the motivational state from hunger to satiety via prefeeding the animals before progressive ratio testing. Prefeeding before testing dramatically reduced the breakpoints achieved in control and Cdk5 cKO mice and eliminated the difference between groups $(27.1 \pm 5.2$ for control vs $40.4 \pm 9.5$ for $\mathrm{cKO}$ ) (Fig. $3 C$ ). These data indicate that reduction in incentive motivation for reinforcement completely eliminated the enhanced breakpoint ratio achieved by $\mathrm{Cdk} 5 \mathrm{cKO}$ mice. Furthermore, $\mathrm{Cdk} 5 \mathrm{cKO}$ and control mice consumed the same amount of food during prefeeding, suggesting that there was likely no difference in hunger or appetite before testing (supplemental Fig. 1C, available at www.jneurosci.org as supplemental material). Together, these data indicate that loss of Cdk5 increased the motivation to obtain reinforcement, likely through enhancement in incentive value. Thus, Cdk5 may govern aspects of reward processing in the mesocorticolimbic-striatal circuitry that are important for natural reinforcers.
Generation of NAc-specific Cdk5 knock-out mouse model

To investigate the role of Cdk5 specifically in neurons of the NAc, we delivered rAAV expressing Cre recombinase to the NAc of fCdk5 mice to excise the Cdk5 allele (Fig. $5 A$ ). rAAV expressing EGFP served as the control vector as described previously (Berton et al., 2006). RNA in situ hybridization analysis on serial coronal brain sections of homozygous fCdk5 mice transduced with Cre indicated a circumscribed loss of Cdk5 mRNA within the NAc that precisely overlaid the area of Cre expression (Fig. 5B). These rAAV vectors are not subject to retrograde transport when delivered to striatal brain regions (Burger et al., 2004). Thus, these results indicate that $\mathrm{KO}$ of Cdk5 occurred specifically within the postsynaptic compartment of NAc neurons (NAc-KO). Delivery of the Cre vectors into wildtype animals exhibited no such effects on Cdk5 expression (data not shown). To evaluate NAc-KO at the protein level, the EGFP signal present in the EGFPCre and the control EGFP vector was used to visualize the specific population of transduced neurons using an epifluorescence microscope. Immunoblots of tissue punch homogenates from EGFPCre fields showed a reduction in Cdk5 protein level to $55.0 \pm 5.1 \%$ of control (Fig. $5 \mathrm{C}$ ). In contrast, transduction by the control EGFP vector had no effect on Cdk5 expression in the NAc (107 $\pm 7.28 \%$ of naive control). Thus, we achieved control of 
A
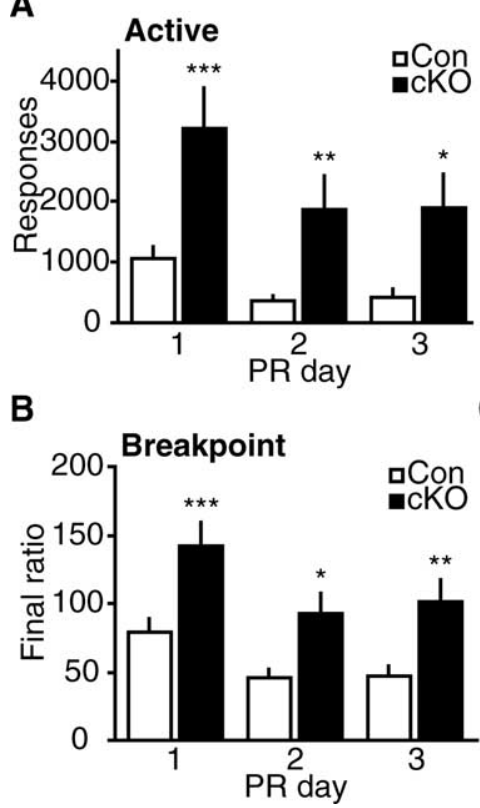

C

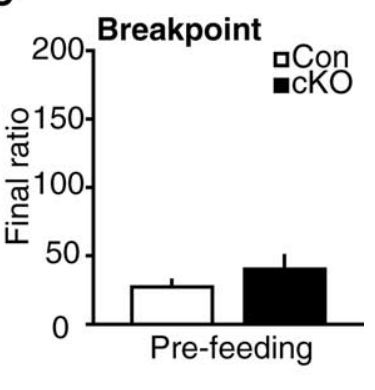

Figure 3. Effect of $\mathrm{Cdk} 5 \mathrm{CKO}$ on instrumental responding for reward. $A$, Performance for control (Con) versus cKO mice for food reinforcement under a PR schedule. The graphs depict active (left) and inactive (right) nose poke responses \pm SEM for 3 consecutive days of PR testing $\left({ }^{*} p<0.05,{ }^{* *} p<0.01,{ }^{* * *} p<0.005\right.$ compared with control, post hoc Tukey, $n=16-20$ per group). $\boldsymbol{B}$, Breakpoints achieved for control versus CKO mice during $3 \mathrm{~d}$ of PR responding. The graphs show mean final ratios achieved $\pm \operatorname{SEM}\left({ }^{*} p<0.05\right.$, ${ }^{* *} p<0.01$, ${ }^{* * *} p<0.001$ compared with control, post hoc Tukey, $n=16-20$ per group). C, Performance in progressive ratio instrumental responding after prefeeding.

Cdk5 expression in NAc neurons by rAAV-mediated Cdk5 $\mathrm{NAc}-\mathrm{KO}$.

\section{Effect of NAc-specific loss of Cdk5 on cocaine-induced} behavioral sensitization

Previous studies have suggested that Cdk5 contributes to the development and expression of locomotor sensitization to cocaine (Bibb et al., 2001; Taylor et al., 2007). However, these studies used pharmacological inhibition of Cdk5 that likely had both presynaptic and postsynaptic effects in the NAc. To investigate the role of Cdk5 specifically in the postsynaptic compartment of striatal neurons, we used rAAV-mediated Cre delivery to the NAc. Notably, NAc-KO did not alter spontaneous activity or anxiety compared with controls (supplemental Fig. 2, available at www. jneurosci.org as supplemental material). With this NAc-KO strategy, we were able to study the effect of selective, postsynaptic Cdk5 loss on locomotor responses to cocaine. Adult, fCdk 5 mice were targeted with rAAV expressing EGFP or Cre (EGFPCre or $\mathrm{Cre}$ ) into the NAc and assessed for cocaine-induced locomotor sensitization to 10 and $15 \mathrm{mg} / \mathrm{kg}$ cocaine doses (Fig. 6). After habituation to saline injections in the locomotor chambers, mice were injected with $10 \mathrm{mg} / \mathrm{kg}$ cocaine for 5 consecutive days, and locomotor responses were recorded for $60 \mathrm{~min}$ (Fig. 6A). There was a main effect of treatment day on locomotor responses in the first $30 \mathrm{~min}$ after saline injection and $5 \mathrm{~d}$ of cocaine $\left(F_{(5,160)}=\right.$ 7.85; $p<0.0001$, two-way RM ANOVA), and locomotion increased over consecutive days to repeated cocaine injections. However, Cdk5 NAc-KO mice showed significantly higher locomotor counts as early as day 3 of cocaine treatment (336.4 \pm 126.3 vs $52.2 \pm 7.3$ for saline), whereas the control mice only showed increases in locomotion on day 5 of cocaine (300.1 \pm 101.8 vs $58.1 \pm 14.3$ for saline) (Fig. $6 A$ ). These data indicate that
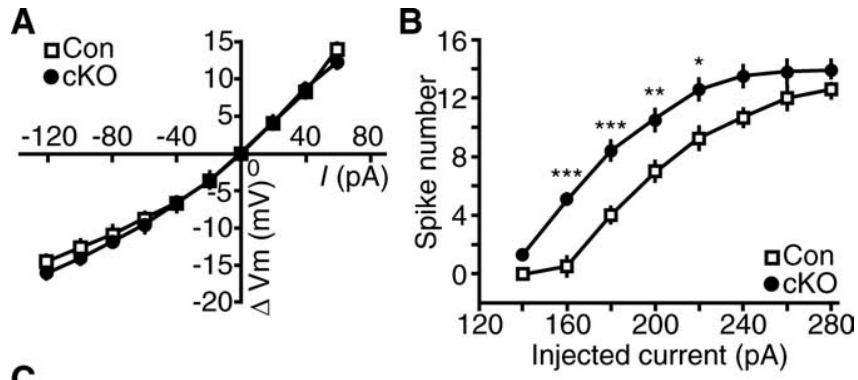

C
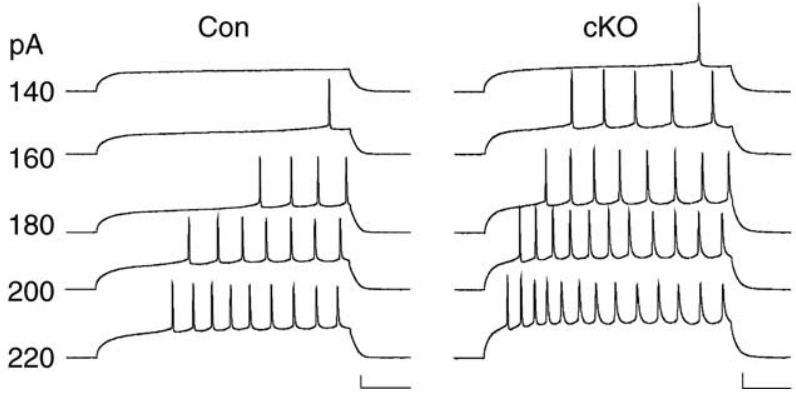

Figure 4. Effect of $\mathrm{Cdk} 5 \mathrm{cK} 0$ on intrinsic membrane excitability of NAc neurons. A, Currentvoltage graphs in NAc neurons from control (Con) and $\mathrm{CKO}$ mice showing no effect on passive membrane properties. $\boldsymbol{B}$, Analysis of intrinsic excitability of NAc neurons from control versus cKO mice. The graph shows mean spike number \pm SEM in response to different current injections $\left({ }^{*} p<0.05,{ }^{* *} p<0.01\right.$, ${ }^{* * *} p<0.001$ compared with control, post hoc Bonferroni, $n=$ 7-8 per group). $C$, Representative traces of action potential firing evoked by depolarizing current pulses (140-220 pA; $500 \mathrm{~ms}$ ) in NAc neurons from control and cKO mice. Calibration: 20 $\mathrm{mV}, 100 \mathrm{~ms}$.

Table 1. Membrane properties of NAc medium spiny neurons from control and Cdk5 cKO mice

\begin{tabular}{lll}
\hline & Control & Cdk5 cK0 \\
\hline Resting membrane potential (mV) & $-81.8 \pm 2.2$ & $-78.7 \pm 1.0$ \\
Rheobase (pA) & $158.3 \pm 4.2$ & $137.6 \pm 5.3^{*}$ \\
Latency to first spike (ms) & $312.8 \pm 45.3$ & $155.0 \pm 20.5^{*}$ \\
Spike threshold (mV) & $-42.8 \pm 0.7$ & $-41.2 \pm 1.2$ \\
Spike amplitude (mV) & $72.4 \pm 3.4$ & $70.3 \pm 2.5$ \\
Spike half-width (ms) & $1.4 \pm 0.2$ & $1.5 \pm 0.3$ \\
\hline
\end{tabular}

Rheobase value was determined as the smallest current injection that elicited a single spike. Latency to first spike was measured from $180 \mathrm{pA}$ current injection. Values are expressed as mean \pm SEM. ${ }^{*} p<0.05$, Student's test, $n=$ 7-8 per group.

Cdk5 loss in the postsynaptic compartment of the NAc enhanced the behavioral sensitization to $10 \mathrm{mg} / \mathrm{kg}$ cocaine exposure.

When mice were analyzed for the development of sensitization using a higher dose of $15 \mathrm{mg} / \mathrm{kg}$ cocaine, no such differences between EGFP and Cre animals were appreciated (Fig. 6 B). Both groups showed robust locomotor sensitization to this higher cocaine dose $\left(F_{(5,165)}=51.3 ; p<0.0001\right.$, two-way RM ANOVA), with both genotypes exhibiting progressive increases in locomotor activity over subsequent challenge days. These effects were observed on day 3 for both control mice (501.6 \pm 83.9 vs $74.8 \pm$ 11.9 for saline) and Cdk5 NAc-KO mice (496.8 \pm 83.1 vs $74.2 \pm$ 10.8 for saline). Statistical analyses revealed no main effect of genotype $\left(F_{(5,165)}=0.00 ; p=0.99\right)$ and no interaction between genotype and treatment day $\left(F_{(5,165)}=0.55 ; p=0.74\right)$. Furthermore, the overall level of behavioral sensitization to $5 \mathrm{~d}$ of 15 $\mathrm{mg} / \mathrm{kg}$ cocaine exposure was not altered between genotypes $(663.2 \pm 91.3$ for control vs $751.6 \pm 98.0$ for NAc-KO). Together, these data indicate that loss of Cdk 5 specifically from the postsynaptic compartment of NAc neurons caused a leftward shift in the threshold to induce behavioral sensitization, but did not alter the maximal behavioral responses to repeated cocaine exposure. 
A

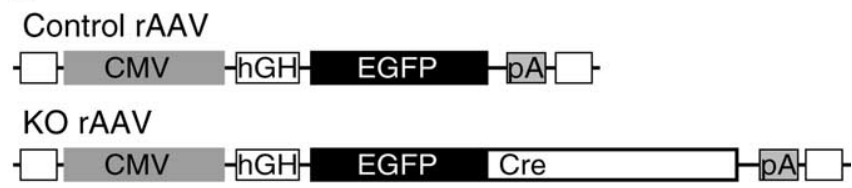

B
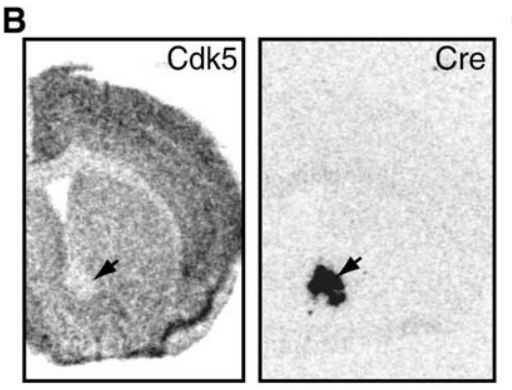

C

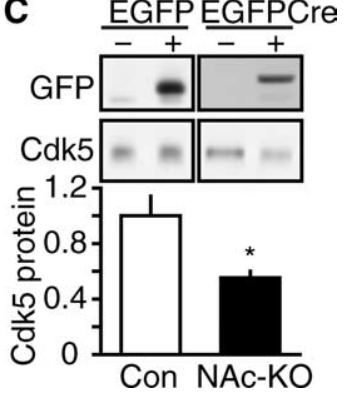

Figure 5. Generation of NAc-specific Cdk5 knock-out mouse model. $A$, Diagram depicting recombinant viral vectors to mediate excision of $\mathrm{Cdk} 5$ in NAc. Viral constructs contain CMV promoter (CMV), human growth hormone intron ( $\mathrm{hGH}$ ), SV40 polyadenylation sequence (pA), and inverted terminal repeats (open squares). The control vector contains an EGFP cassette, whereas the $\mathrm{KO}$ vector expresses a chimeric EGFPCre protein. $\boldsymbol{B}$, Representative in situ hybridization analysis of rAAV-mediated NAC-specific knock-out of Cdk5. Arrows indicate corresponding NAc regions of rAAV transduction in adjacent sections hybridized with C $\mathrm{dk5}$ (left) and Cre (right) riboprobes after rAAV-EGFPCre delivery. C, Quantitative immunoblotting of rAAVmediated NAC-KO. Representative immunoblots of GFP and C $d k 5$ in homogenates from mice transduced with rAAV expressing EGFP (left) or EGFPCre (right) are shown in the top panels. GFP immunoblots show detection of EGFP ( $\sim 28 \mathrm{kDa})$ in control samples and EGFPCre $(\sim 70 \mathrm{kDa})$ in NAc-K0 samples. Quantitation of ( $\mathrm{dk} 5$ levels in NAc lysates transduced with EGFP (Con) versus EGFPCre (NAC-KO) is shown at bottom ( ${ }^{*} p<0.05$, Student's $t$ test; $n=4$ per group).

\section{Effect of NAc-specific Cdk5 KO on expression of cocaine- conditioned place preference}

Drug addiction involves associative learning processes in which the reinforcing properties of drugs become associated with environmental cues. To assess the role of Cdk5 in this aspect of reward-related learning that likely has relevance for recidivism, Cdk5 NAc-KO mice were analyzed for cocaine-conditioned place preference. In this paradigm, cocaine exposure is paired with a distinctive context to associate cocaine reinforcement with specific contextual cues. After cocaine conditioning, the degree of cocaine reinforcement is inferred by the amount of time the mice spend in the previously drug-associated context. Before conditioning, there was no preference for the compartment that was to be paired with cocaine at any dose in either control or NAc-KO mice $\left(F_{(3,101)}=0.23 ; p=0.87\right.$, two-way ANOVA). When conditioned with a low dose of cocaine $(2.5 \mathrm{mg} / \mathrm{kg}), \mathrm{Cdk} 5 \mathrm{NAc}-\mathrm{KO}$ mice displayed a significant increase in time spent in the drugpaired context $(644.7 \pm 41.4$ during posttraining vs $520.5 \pm 23.1$ for pretraining) (Fig. 7A), whereas no place preference was found in control animals $(574.7 \pm 42.8$ during posttraining vs $522.5 \pm$ 35.9 for pretraining) (Fig. 7A). These data indicate that postsynaptic loss of Cdk5 in NAc neurons may facilitate cocaine-induced associative learning. Training with either 5 or $20 \mathrm{mg} / \mathrm{kg}$ cocaine induced significant increases in the amount of time spent in the cocaine-associated compartment in both control and NAc-KO mice (Fig. 7A). Furthermore, analysis of the conditioning score for each group indicated that training induced a significant preference at all cocaine doses in Cdk5 NAc-KO mice compared with saline, whereas control mice showed preferences after only 5 and $20 \mathrm{mg} / \mathrm{kg}$ training doses compared with saline (Fig. 7B). Together, these data suggest that deletion of Cdk5 from neurons of the NAc reduced the threshold for cocaine-conditioned place preference. This finding is consistent with the enhanced psychomotor effects of cocaine seen in Cdk5 NAc-KO mice in the locomotor sensitization assay and further supports the notion that Cdk5 regulates cocaine-related behavioral responses, at least in part, through activity in striatal neurons of the NAc.

\section{Discussion}

The present study demonstrates that loss of Cdk5 in the adult forebrain enhances the locomotor activating properties of cocaine, augments motivation for food reinforcement, and increases intrinsic neuronal excitability in the NAc. Enhancements in the psychoactive properties of cocaine were also induced by selective loss of Cdk5 in postsynaptic compartments of the NAc. These findings are consistent with the hypothesis that Cdk5 regulates dopamine neurotransmission in the NAc and serves as a homeostatic target of chronic psychostimulant exposure. Two model systems were used here that allowed restricted loss of Cdk5 activity: first, a transgenic $\mathrm{Cdk} 5 \mathrm{cKO}$ system was developed that allowed temporal and spatial control of Cdk5 expression selectively in the adult forebrain. Second, rAAV was used to induce loss of Cdk5 restricted to the postsynaptic compartment of NAc neurons in adult animals (i.e., NAc-KO). This targeted deletion of Cdk5 in the NAc facilitated cocaine-induced locomotor sensitization and conditioned place preference for cocaine. Together these results provide compelling evidence that $\mathrm{Cdk} 5$ acts as a key negative regulator of neuronal excitability in the NAc through postsynaptic mechanisms that may underlie enhanced neuroadaptive and motivational properties of addictive drugs and natural reinforcers.

Although previous studies have used the infusion of Cdk5 inhibitors into the brain in combination with behavioral assessments (Bibb et al., 2001; Chen and Chen, 2005; Taylor et al., 2007), the development of conditional Cdk5 knock-out model systems allowed for direct evaluation of the role of Cdk5 in the psychoactive properties of cocaine and reward-motivated behavior. Indeed, these approaches circumvent the limitations of Cdk5 inhibitors, including the inability to localize the effects of Cdk5 inhibition to either presynaptic or postsynaptic compartments and the possibility of nonspecific pharmacological effects. Furthermore, inhibition of Cdk5 catalytic activity may not affect structural or activity-independent roles of the protein, which have recently been appreciated (Hawasli and Bibb, 2007). Thus, conditional knock-out strategies provide a powerful platform from which to evaluate the role of Cdk5 in reward-related behavior. In the present study, conditional Cdk5 knock-out allowed the restricted and selective loss of Cdk5 in adult brain to be more directly linked to behavioral response to rewarding stimuli.

The reinforcing and rewarding properties of drugs of abuse are associated with potent activation of the mesocorticolimbicstriatal circuitry controlled by dopamine neurotransmission. Cdk5 negatively regulates dopamine signal transduction (Bibb et al., 1999), and pharmacological inhibition of Cdk5 in the NAc enhances several locomotor and motivational responses to cocaine (Bibb et al., 2001; Taylor et al., 2007). Here, we show that CaMKII-Cre Cdk5 cKO mice, in which Cdk5 is deleted in the adult brain, display potentiated locomotor responses to cocaine. Specifically, loss of Cdk5 throughout the forebrain, including the mesocorticolimbic-striatal circuitry, increased the locomotor response to the highest dose of cocaine in a randomized doseresponse study. These data are consistent with previous studies where Cdk5 inhibition enhanced locomotor responses to cocaine (Bibb et al., 2001; Taylor et al., 2007) and suggest that Cdk5 
activity in the adult forebrain is involved in the modulation of the psychoactive effects of cocaine exposure.

Dopamine neurotransmission plays important roles in multiple rewardrelated behavioral processes in addition to those invoked by addictive drugs. To investigate whether Cdk5 is also involved in nondrug reward-related behavior, we evaluated the consequences of loss of Cdk5 on instrumental responding for food reinforcement. Cdk5 $\mathrm{cKO}$ mice displayed increased incentive motivation for food-reinforcement measured by progressive ratio responding. It should be noted that although the CaMKII-Cre Cdk5 cKO model system avoids the possible confounds of congenital abnormalities and pharmacological nonspecificity, the loss of Cdk 5 is not complete in this model system (Fig. 1). Nonetheless, the observations made here are consistent with Cdk5 inhibition enhancing cocaine-induced potentiation of conditioned reinforcement and progressive ratio responding for cocaine (Taylor et al., 2007) and strongly suggest that Cdk5 activity influences reward-motivated processes that involve dopamine signaling in the NAc.

The development of locomotor sensitization may model aspects of the neuroadaptive processes that occur in the mesocorticolimbic-striatal circuitry in response to repeated drug exposure. In previous studies, pharmacological inhibition of Cdk5 in the NAc enhanced the maximal activity level to repeated cocaine exposure (Bibb et al., 2001; Taylor et al., 2007). However, as mentioned above, these pharmacological manipulations cannot distinguish presynaptic versus postsynaptic effects of Cdk5 inhibition. Furthermore, the effect of pharmacological inhibitors is restricted to catalytic activity, whereas knock-out removes the protein with consequences for both activity-dependent and independent functions of Cdk5. In the current study, selective postsynaptic knock-out of Cdk5 in neurons of the NAc using infusions of rAAV lowered the threshold for cocaine-induced locomotor sensitization. The maximal activity level achieved after repeated cocaine exposure was, however, not affected. Based on the behavioral differences in these models, it may be speculated that Cdk5 activities in the presynaptic versus postsynaptic compartments of the mesocorticolimbic-striatal circuitry have complementary yet possibly distinct actions. Although we are cautious in drawing conclusions from such different models, the present data derived from NAc-specific KO suggest that Cdk5 activity in NAc neurons may regulate the threshold for the development of neuroadaptations in response to drugs of abuse.

Such drug-induced neuroadaptations also influence the formation of associations between the rewarding properties of the drug and environmental stimuli. We therefore tested Cdk5 $\mathrm{NAc-KO}$ in this form of reward-related learning using the conditioned place preference paradigm. Similar to the effects on locomotor sensitization, selective loss of Cdk5 in the NAc reduced the threshold dose required to induce a conditioned place preference for cocaine. Notably, consistent with the findings from the locomotor sensitization experiment, the maximal behavioral responses to a high dose of cocaine were not affected by Cdk5 NAc-KO. rAAV-mediated NAc-specific loss of Cdk5 allowed the role of this kinase to be assessed in a specific compartment of the mesocorticolimbic-striatal circuitry and alleviated the need for transgenic Cre mice. However, it should be noted that this viral approach for spatially restricted transgene delivery is dictated by serotype, viral-receptor, and promoter considerations (Shevtsova et al., 2005). Nonetheless, these data suggest that Cdk5 in the NAc is critical for regulating the threshold or sensitivity of the effects of cocaine on neuroplasticity and rewardrelated learning.

Striatal medium spiny neurons are the primary output of the mesocorticolimbic-striatal circuitry that mediates behavioral responses to reward-related stimuli. At this critical point of convergence, the signal transduction cascades activated by cocaine result in increased striatal excitability (Dong et al., 2006). Indeed, dopamine regulates striatal neuron firing through PKAdependent signaling (Hernandez-Lopez et al., 1997), and chronic cocaine exposure has also been reported to decrease the excitability of rat striatal neurons (Zhang et al., 1998). Because the signaling mechanisms underlying decreases in striatal excitability in cocaine-exposed animals remain unknown, we performed an electrophysiological analysis of the properties of NAc neurons from Cdk5 cKO mice. This experiment revealed a dramatic increase in intrinsic excitability in NAc medium spiny neurons after a loss of Cdk5, suggesting that Cdk5 has inhibitory influences not only on dopamine neurotransmission, but also on the intrinsic firing properties of NAc neurons. Moreover, these findings implicate Cdk 5 in the regulation of striatal neuron responsiveness to excitatory neurotransmission, such as that mediated via glutamatergic input from cortical afferents. The present studies illustrate the functional relevance of regulation of striatal excitability in the mesocorticolimbic-striatal circuit and suggest that cocaineregulated targets, such as Cdk5, may influence the electrophysiological properties of striatal output neurons. Because Cdk5 controls the efficacy of dopamine and PKA-dependent signaling via the phosphorylation of DARPP-32 at Thr75 in the striatum (Bibb et al., 1999; Benavides and Bibb, 2004), the current data support the hypothesis that Cdk5 may modulate striatal neuron excitability via regulation of PKA activity. Future studies will undoubtedly 
A

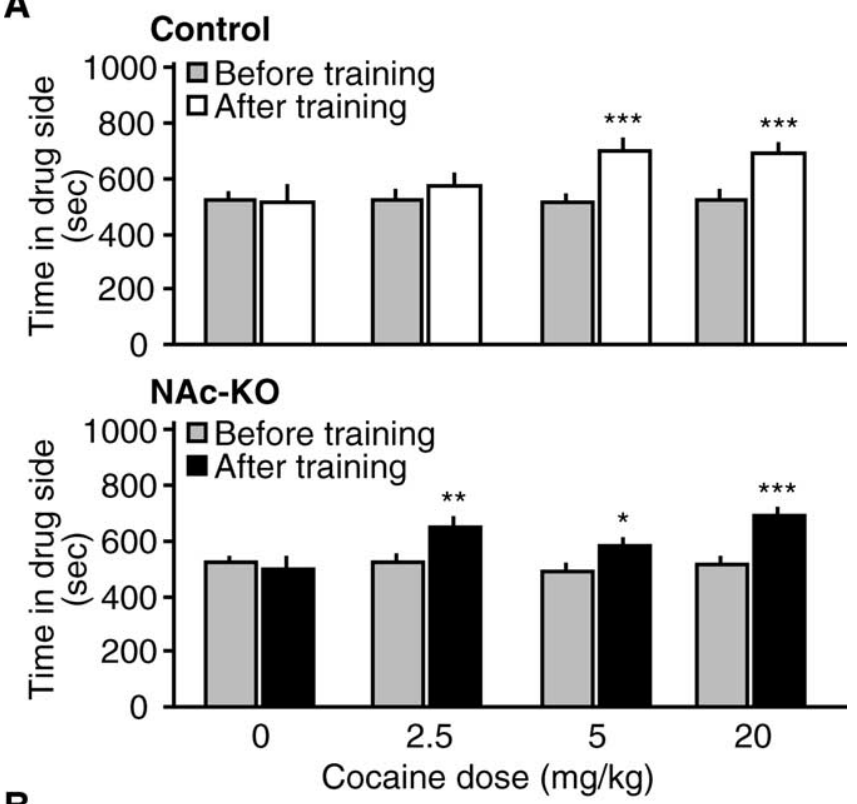

B

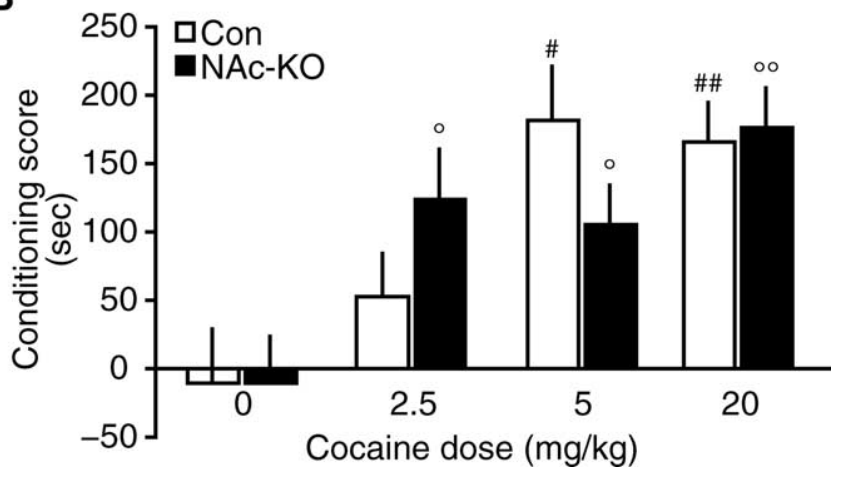

Figure 7. Effect of NAc-specific C $\mathrm{dk} 5 \mathrm{~K} 0$ on cocaine-conditioned place preference. $A$, Time spent in drug-paired compartment for control and NAc-KO mice. Top graph depicts performance of control mice before (gray) and after (white) cocaine training at the indicated cocaine doses. Bottom graph depicts (dk5 NAc-KO mice performance before (gray) and after (black) cocaine training. Mean time spent in drug compartment \pm SEM is indicated for each group at each training dose of cocaine ${ }^{*} p<0.05,{ }^{* *} p<0.01,{ }^{* * *} p<0.001$, paired $t$ test; $n=9-19$ per group). $\boldsymbol{B}$, Analysis of conditioning scores calculated from performance before and after training for each dose indicated. The graph depicts mean conditioning score \pm SEM in control (Con, ${ }^{\#} p<0.05,{ }^{\# \#} p<0.01$ compared with saline, post hoc Newman-Keuls; $n=9-19$ per group) versus (dk5 NAc-KO $\left({ }^{\circ} p<0.05,{ }^{\circ} p<0.01\right.$ compared with saline, post hoc NewmanKeuls; $n=12-18$ per group) mice for the cocaine dose indicated.

identify additional mechanisms by which Cdk5 may regulate cocaine sensitivity and motivation. Here we demonstrate that elevation in striatal neuron intrinsic excitability in $\mathrm{Cdk} 5 \mathrm{cKO}$ mice is associated with parallel enhancements in behavioral responses to reinforcing stimuli, either drugs or food. These findings underscore the importance of understanding how $\mathrm{Cdk} 5$ alters the functional properties of ion channels that mediate striatal neuron firing, because these mechanisms may serve as novel targets for the treatment of addiction and disorders of motivation.

\section{References}

Benavides DR, Bibb JA (2004) Role of Cdk5 in drug abuse and plasticity. Ann NY Acad Sci 1025:335-344.

Berton O, McClung CA, Dileone RJ, Krishnan V, Renthal W, Russo SJ, Graham D, Tsankova NM, Bolanos CA, Rios M, Monteggia LM, Self DW, Nestler EJ (2006) Essential role of BDNF in the mesolimbic dopamine pathway in social defeat stress. Science 311:864-868.
Bibb JA (2003) Role of Cdk5 in neuronal signaling, plasticity, and drug abuse. Neurosignals 12:191-199.

Bibb JA, Snyder GL, Nishi A, Yan Z, Meijer L, Fienberg AA, Tsai LH, Kwon YT, Girault JA, Czernik AJ, Huganir RL, Hemmings Jr HC, Nairn AC, Greengard P (1999) Phosphorylation of DARPP-32 by Cdk5 modulates dopamine signalling in neurons. Nature 402:669-671.

Bibb JA, Chen J, Taylor JR, Svenningsson P, Nishi A, Snyder GL, Yan Z, Sagawa ZK, Ouimet CC, Nairn AC, Nestler EJ, Greengard P (2001) Effects of chronic exposure to cocaine are regulated by the neuronal protein Cdk5. Nature 410:376-380.

Burger C, Gorbatyuk OS, Velardo MJ, Peden CS, Williams P, Zolotukhin S, Reier PJ, Mandel RJ, Muzyczka N (2004) Recombinant AAV viral vectors pseudotyped with viral capsids from serotypes 1,2, and 5 display differential efficiency and cell tropism after delivery to different regions of the central nervous system. Mol Ther 10:302-317.

Cai XH, Tomizawa K, Tang D, Lu YF, Moriwaki A, Tokuda M, Nagahata S, Hatase O, Matsui H (1997) Changes in the expression of novel Cdk5 activator messenger RNA (p39nck5ai mRNA) during rat brain development. Neurosci Res 28:355-360.

Centonze D, Costa C, Rossi S, Prosperetti C, Pisani A, Usiello A, Bernardi G, Mercuri NB, Calabresi P (2006) Chronic cocaine prevents depotentiation at corticostriatal synapses. Biol Psychiatry 60:436-443.

Chen J, Kelz MB, Hope BT, Nakabeppu Y, Nestler EJ (1997) Chronic Fosrelated antigens: stable variants of deltaFosB induced in brain by chronic treatments. J Neurosci 17:4933-4941.

Chen PC, Chen JC (2005) Enhanced Cdk5 activity and p35 translocation in the ventral striatum of acute and chronic methamphetamine-treated rats. Neuropsychopharmacology 30:538-549.

Chergui K, Svenningsson P, Greengard P (2004) Cyclin-dependent kinase 5 regulates dopaminergic and glutamatergic transmission in the striatum. Proc Natl Acad Sci USA 101:2191-2196.

Dong Y, Green T, Saal D, Marie H, Neve R, Nestler EJ, Malenka RC (2006) CREB modulates excitability of nucleus accumbens neurons. Nat Neurosci 9:475-477.

Evans GJO, Cousin MA (2007) Activity-dependent control of slow synaptic vesicle endocytosis by cyclin-dependent kinase 5. J Neurosci 27:401-411.

Fischer A, Sananbenesi F, Pang PT, Lu B, Tsai LH (2005) Opposing roles of transient and prolonged expression of p25 in synaptic plasticity and hippocampus-dependent memory. Neuron 48:825-838.

Gold SJ, Ni YG, Dohlman HG, Nestler EJ (1997) Regulators of G-protein signaling (RGS) proteins: region-specific expression of nine subtypes in rat brain. J Neurosci 17:8024-8037.

Hawasli AH, Bibb JA (2007) Alternative roles for Cdk5 in learning and synaptic plasticity. Biotechnol J 2:941-948.

Hawasli AH, Benavides DR, Nguyen C, Kansy JW, Hayashi K, Chambon P, Greengard P, Powell CM, Cooper DC, Bibb JA (2007) Cyclindependent kinase 5 governs learning and synaptic plasticity via control of NMDAR degradation. Nat Neurosci 10:880-886.

Hernandez-Lopez S, Bargas J, Surmeier DJ, Reyes A, Galarraga E (1997) D1 receptor activation enhances evoked discharge in neostriatal medium spiny neurons by modulating an L-type $\mathrm{Ca}^{2+}$ conductance. J Neurosci 17:3334-3342.

Hommel JD, Sears RM, Georgescu D, Simmons DL, DiLeone RJ (2003) Local gene knockdown in the brain using viral-mediated RNA interference. Nat Med 9:1539-1544.

Hope BT, Nye HE, Kelz MB, Self DW, Iadarola MJ, Nakabeppu Y, Duman RS, Nestler EJ (1994) Induction of a long-lasting AP-1 complex composed of altered Fos-like proteins in brain by chronic cocaine and other chronic treatments. Neuron 13:1235-1244.

Hyman SE, Malenka RC (2001) Addiction and the brain: the neurobiology of compulsion and its persistence. Nat Rev Neurosci 2:695-703.

Kansy JW, Daubner SC, Nishi A, Sotogaku N, Lloyd MD, Nguyen C, Lu L, Haycock JW, Hope BT, Fitzpatrick PF, Bibb JA (2004) Identification of tyrosine hydroxylase as a physiological substrate for Cdk5. J Neurochem 91:374-384.

Kansy JW, Katsovich L, McIver KS, Pick J, Zabriskie JB, Lombroso PJ, Leckman JF, Bibb JA (2006) Identification of pyruvate kinase as an antigen associated with Tourette syndrome. J Neuroimmunol 181:165-176.

Kelley AE, Berridge KC (2002) The neuroscience of natural rewards: relevance to addictive drugs. J Neurosci 22:3306-3311.

Ko J, Humbert S, Bronson RT, Takahashi S, Kulkarni AB, Li E, Tsai LH 
(2001) p35 and p39 are essential for cyclin-dependent kinase 5 function during neurodevelopment. J Neurosci 21:6758-6771.

Kumar A, Choi KH, Renthal W, Tsankova NM, Theobald DE, Truong HT, Russo SJ, Laplant Q, Sasaki TS, Whistler KN, Neve RL, Self DW, Nestler EJ (2005) Chromatin remodeling is a key mechanism underlying cocaineinduced plasticity in striatum. Neuron 48:303-314.

Kwon YT, Tsai LH (1998) A novel disruption of cortical development in p35(-/-) mice distinct from reeler. J Comp Neurol 395:510-522.

Lew J, Huang QQ, Qi Z, Winkfein RJ, Aebersold R, Hunt T, Wang JH (1994) A brain-specific activator of cyclin-dependent kinase 5. Nature 371:423-426.

Luikart BW, Nef S, Virmani T, Lush ME, Liu Y, Kavalali ET, Parada LF (2005) TrkB has a cell-autonomous role in the establishment of hippocampal Schaffer collateral synapses. J Neurosci 25:3774-3786.

Monteggia LM, Luikart B, Barrot M, Theobold D, Malkovska I, Nef S, Parada LF, Nestler EJ (2007) Brain-derived neurotrophic factor conditional knockouts show gender differences in depression-related behaviors. Biol Psychiatry 61:187-197.

Moy LY, Tsai LH (2004) Cyclin-dependent kinase 5 phosphorylates serine 31 of tyrosine hydroxylase and regulates its stability. J Biol Chem 279:54487-54493

Nestler EJ (2001) Molecular basis of long-term plasticity underlying addiction. Nat Rev Neurosci 2:119-128.

Nikolic M, Dudek H, Kwon YT, Ramos YF, Tsai LH (1996) The cdk5/p35 kinase is essential for neurite outgrowth during neuronal differentiation. Genes Dev 10:816-825.

Ohshima T, Ward JM, Huh CG, Longenecker G, Veeranna, Pant HC, Brady RO, Martin LJ, Kulkarni AB (1996) Targeted disruption of the cyclindependent kinase 5 gene results in abnormal corticogenesis, neuronal pathology and perinatal death. Proc Natl Acad Sci USA 93:11173-11178.

Sahin B, Kansy JW, Nairn AC, Spychala J, Ealick SE, Fienberg AA, Greene RW, Bibb JA (2004) Molecular characterization of recombinant mouse adenosine kinase and evaluation as a target for protein phosphorylation. Eur J Biochem 271:3547-3555.

Shevtsova Z, Malik JM, Michel U, Bahr M, Kugler S (2005) Promoters and serotypes: targeting of adeno-associated virus vectors for gene transfer in the rat central nervous system in vitro and in vivo. Exp Physiol 90:53-59.

Srinivas S, Watanabe T, Lin CS, William CM, Tanabe Y, Jessell TM, Costan- tini F (2001) Cre reporter strains produced by targeted insertion of EYFP and ECFP into the ROSA26 locus. BMC Dev Biol 1:4.

Tan TC, Valova VA, Malladi CS, Graham ME, Berven LA, Jupp OJ, Hansra G, McClure SJ, Sarcevic B, Boadle RA, Larsen MR, Cousin MA, Robinson PJ (2003) Cdk5 is essential for synaptic vesicle endocytosis. Nat Cell Biol 5:701-710.

Taylor JR, Lynch WJ, Sanchez H, Olausson P, Nestler EJ, Bibb JA (2007) Inhibition of Cdk5 in the nucleus accumbens enhances the locomotoractivating and incentive-motivational effects of cocaine. Proc Natl Acad Sci USA 104:4147-4152.

Thomas MJ, Malenka RC (2003) Synaptic plasticity in the mesolimbic dopamine system. Philos Trans R Soc Lond B Biol Sci 358:815-819.

Tomizawa K, Sunada S, Lu YF, Oda Y, Kinuta M, Ohshima T, Saito T, Wei FY, Matsushita M, Li ST, Tsutsui K, Hisanaga S, Mikoshiba K, Takei K, Matsui H (2003) Cophosphorylation of amphiphysin I and dynamin I by Cdk5 regulates clathrin-mediated endocytosis of synaptic vesicles. J Cell Biol 163:813-824

Tsai LH, Delalle I, Caviness Jr VS, Chae T, Harlow E (1994) p35 is a neuralspecific regulatory subunit of cyclin-dependent kinase 5. Nature 371:419-423.

Tsien JZ, Chen DF, Gerber D, Tom C, Mercer EH, Anderson DJ, Mayford M, Kandel ER, Tonegawa S (1996) Subregion- and cell type-restricted gene knockout in mouse brain. Cell 87:1317-1326.

Ungless MA, Whistler JL, Malenka RC, Bonci A (2001) Single cocaine exposure in vivo induces long-term potentiation in dopamine neurons. Nature 411:583-587.

Wattler S, Kelly M, Nehls M (1999) Construction of gene targeting vectors from lambda KOS genomic libraries. Biotechniques 26:1150-1156, 1158, 1160.

Zhang XF, Hu XT, White FJ (1998) Whole-cell plasticity in cocaine withdrawal: reduced sodium currents in nucleus accumbens neurons. J Neurosci 18:488-498.

Zhong P, Gu Z, Wang X, Jiang H, Feng J, Yan Z (2003) Impaired modulation of GABAergic transmission by muscarinic receptors in a mouse transgenic model of Alzheimer's disease. J Biol Chem 278:26888-26896.

Zolotukhin S, Byrne BJ, Mason E, Zolotukhin I, Potter M, Chesnut K, Summerford C, Samulski RJ, Muzyczka N (1999) Recombinant adenoassociated virus purification using novel methods improves infectious titer and yield. Gene Ther 6:973-985. 